\title{
Haverá outro código para a Medicina?
}

\author{
Paulo Rosenbaum* \\ Universidade de São Paulo (USP) | São Paulo, Brasil \\ rosenbau@usp.br
}

O que é um código? Pode ser uma coleção metódica e sistemática de leis, uma coleção de regras sistemáticas de procedimento e conduta, ou um sistema de sinais secretos ou convencionais usados no comércio e na literatura. O título do meu livro O outro código da medicina no século XXI ${ }^{1}$ insinua que pode haver mais de uma compreensão para a medicina, pode haver mais de um código de procedimento e conduta para compreender saúde e enfermidade. Um não exclui, necessariamente, o outro. Vários códigos podem conviver e ser, simultaneamente, usados, sem que um tenha supremacia sobre o outro.

O público que consome livros científicos conhece pouco de medicina preventiva e tem noções muito vagas sobre as medicinas integrativas. $O$ conceito popular é de que a prevenção não é solução e de que uma medicina menos invasiva, como a das medicinas integrativas, paira aspectos polêmicos. A verdade é que a grande maioria desse público as conhece apenas superficialmente. Poucos a conhecem como uma medicina que cuida de sujeitos. Outros não têm a menor ideia de sua abrangente capacidade de atuação que vai dos doentes com patologias severas às pessoas com problemas clínicos sem diagnóstico definido. Enfim, que a prevenção pode atuar no indefinível estado chamado de "mal estar". Esse "mal estar" (illness) indevidamente pouco valorizado, também é muito importante na medicina, pois aparece muito antes de que a patologia (disease), a doença propriamente dita. se organize e apareça na forma de sinais e sintomas. O que menos gente sabe ainda é que a homeopatia interfere em todas essas áreas levando em consideração também o estado de saúde.

E por que o grande público sabe tão pouco sobre ela ou a conhece de forma tão estereotipada?

A homeopatia, como sabemos, é uma medicina sobrevivente. As provas são sua longa permanência na adversidade e sua lenta, porém sustentada expansão. As referências são escassas em todo tipo de mídia, especialmente quanto aos seus aspectos efetivamente mais interessantes. A omissão crônica do seu verdadeiro alcance, bem como o de outras medicinas integrativas também explica e justifica sua baixa visibilidade.

A homeopatia pode ser definida como um sistema terapêutico de interferência médica baseada em similitude e observação clínica que usa a individualização dos sintomas

\footnotetext{
* Médico e Doutor em Ciências pela Universidade de São Paulo, poeta e romancista.

${ }^{1}$ ROSENBAUM, Paulo. O outro código da medicina no século XXI. [S.1.]: Sambation Edit, 2015.
} 
como sua principal fonte de conhecimento. Trata-se de uma prática médica que ouve histórias, acolhe narrativas e interpreta biografias. Não é fortuito que estejam nascendo movimentos como "Medicina baseada em narrativas", "Medicina sem pressa", "Medicina baseada em empatia", "Hermenêutica médica".

No romance Céu subterrâneo, ${ }^{2}$ trago uma referência do clássico de Aristóteles o tratado História dos animais. Numa determinada passagem desse texto, ele escreve sobre a memória. Por um erro de interpretação, conhecemos a famosa versão de que o homem seria racional em oposição aos animais que estariam descritos como irracionais. Para o filósofo, no entanto, a verdadeira distinção seria outra, e está em uma passagem desse mesmo livro: o que nos diferencia dos outros animais não seria a possibilidade de raciocinar, pois é evidente que os animais também o fazem. Para o pensador, a grande distinção estaria na capacidade humana para evocar a memória conforme sua vontade. E narrá-la.

Cito isso para lembrar que Prof. Walter E. Maffei, importante pesquisador e neuropatologista brasileiro e um dos meus principais mestres, ilustrava uma de suas aulas na Faculdade de Medicina projetando imagens de gatos. Por quê? Afirmava, com razão, que aqueles que tinham as predisposições alérgicas despertada por alguma idiossincrasia, poderiam apresentá-las apenas com a "lembrança" dessa experiência. Não seria necessária a presença física de um gato, bastaria imaginar à exposição a algum alérgeno que não estivesse presente para "excitar" instantaneamente um quadro alérgico. A lembrança de alguém que apresenta sensibilidade ao pelo desse animal poderia desencadear um início de manifestação alérgica. Esse exemplo evidencia pelos menos duas coisas: a incrível e abrangente sensibilidade do psiquismo e o papel da memória em nossa saúde.

Muitos aspectos permanecem misteriosos na clínica. Não é incomum que os pacientes desenvolvam estranhas e desconhecidas sensibilidades aos produtos farmacêuticos e alimentícios mais comuns. Ou sujeitos que sentem súbito mal-estar quando terremotos estavam para ocorrer a milhares de quilômetros dali. Sabemos que muitas pessoas têm perturbações cardiocirculatórias e respiratórias antes e durante os fenômenos climáticos. Existem vários relatos de pressentimentos e sintomas inexplicáveis que, normalmente, não seriam relevantes para uma aplicação da técnica de tratamento, mas extremamente importantes para a compreensão da história clínica de alguns indivíduos.

Não se trata de um fenômeno religioso ou de uma mistificação. Temos que recordar que, para a genuína investigação científica, sempre existirão mais perguntas do que respostas.

O homem não é mero contemplador de seu habitat ou do sistema de tratamento médico que escolhe. Como todo ser vivo, ele pertence ao ecossistema. $\mathrm{O}$ tempo age

2 ROSENBAUM, Paulo. Céu subterrâneo. São Paulo: Perspectiva, 2016. 
sobre ele, e simultaneamente, ele sofre múltiplas influências do meio no qual habita. A meteorobiologia, hoje uma disciplina, nos ensina o poder das meiopragias sobre os seres. Quando aumentam as manchas solares, ocorrem ciclos epidêmicos de doenças na Terra, as influências climáticas, barométricas e da poluição atmosférica sobre os estados de saúde são clinicamente evidentes. A despeito de toda tecnociência e da propedêutica armada, o clínico experiente ainda pode observar a incidência maior de crises de gota no outono e de hemorragias na primavera.

Também não é infrequente que médicos sejam pegos de surpresa com o que aprendem das experiências pessoais dos pacientes, de suas sensibilidades e características individuais. Estar atento a esses aspectos não se limita a quem pratica qualquer modalidade de terapêutica integrativa, mas a todos que se dedicam a tarefa de cuidar da saúde dos seres humanos e dos animais.

Costumamos dizer que não há mentira em clínica. O que um paciente sente não pode ser julgado no campo estrito da verdade ou da mentira. Para atestar se um sintoma é falso ou verdadeiro não basta fazer uma investigação clínica que confirme ou não a patologia. Todos os sintomas são, de uma forma ou de outra, verdadeiros, pois mesmo as fantasias, delírios e as interpretações (incluindo as hipocondríacas) fazem parte integrante dos problemas dos sujeitos enfermos.

É importante que médicos, ou qualquer profissional das práticas de saúde, sejam treinados para acolher o que cada pessoa percebe de anômalo ou estranho no funcionamento de seus órgãos e em sua própria vida. Tudo que o paciente informa deveria ser relevante para o médico cuidador, independentemente da correlação que este estabeleça com alguma enfermidade específica. Isso vale para o generalista e para o especialista, para o clínico ou para o cirurgião.

No mundo todo, cresce uma tendência científica: passa a ser cada vez mais importante individualizar as doenças. Como toda uma tradição médica vitalista pensava, incluindo Samuel Hahnemann, é preciso saber como cada doença impacta a saúde de cada pessoa, pois cada um tem uma forma particular de desenvolvê-la e de voltar a ficar saudável. Essa diretriz, preocupação constante de muitos médicos vitalistas na história da medicina, pode fazer toda a diferença.

E não só nos resultados diretos, mas em todo processo de adoecimento, convalescença e recuperação. Como lidar com o desconforto? Às vezes, um tratamento pode ser dolorido e provocar sofrimento. Para a pessoa enferma, é muito importante a assistência, o suporte e a presença de quem cuida. Portanto, um aspecto vital de qualquer tratamento é a qualidade do cuidado que o profissional dispensa ao enfermo.

Pode-se encontrar referências bibliográficas sobre todas essas informações. Essas reflexões são fruto de décadas de observação e testemunhos da clínica médica nos últimos trinta anos. Este texto, que o leitor tem nas mãos, ou na tela, é uma 
condensação de um livro, hoje esgotado, que transformei em e-book sob o título O outro código da medicina.

Às vezes, as pessoas perguntam qual o motivo de - diante de sua eficácia e abrangência clínica, especialmente na atenção primária à saúde na prevenção e no tratamento das moléstias crônicas - a homeopatia nunca ter se universalizado como forma de atendimento. Há décadas, a Organização Mundial de Saúde a recomenda às medicinas tradicionais. Uma publicação recente da Escola de Saúde Pública da Universidade de Harvard $^{3}$ recomendou o uso de homeopatia nos sistemas de atenção primária à saúde. No Brasil, o SUS teve várias tentativas de ampliar o uso de práticas integrativas. Recentemente, a Suíça organizou uma consulta popular e a homeopatia, finalmente, entrou como opção terapêutica no sistema público de saúde. Sabe-se que ela já foi reintroduzida no currículo de escolas de medicina nos EUA. Na Alemanha, além de popular, a homeopatia e as medicinas integrativas têm larga aceitação pelos médicos e é usada por grande porcentagem de clínicos e especialistas como tratamento complementar. Entretanto, o fato e a pergunta persistem: qual é o obstáculo para nunca conseguirem se universalizar como práticas médicas? É importante tentar entender.

São muitos fatores concorrendo simultaneamente. $O$ primeiro e decerto o mais significativo é a dificuldade para estabelecer núcleos de pesquisa que sejam financiados pelo Estado e independentes da pressão dos poderosos lobbies que comandam a indústria farmacêutica. Sem prover centros autônomos de pesquisa com recursos e capacidade política para determinar a prioridade das pesquisas, todo avanço farmacotécnico em medicina fica sujeito à lógica dos dividendos das fábricas e sob o controle de oligopólios fármaco-industriais, conforme sugeriu ainda no início do século 20, o historiador da medicina Henri Sigerist.

Não há nenhuma ingênua tese conspiratória ou anticapitalista nessa observação, apenas a elementar constatação de fatos. É importante reconhecer os muitos avanços das tecnologias médicas e o papel relevante da indústria farmacêutica, ainda que isso não a transforme em um símbolo de benemerência. E é também justo que se pergunte: por que a indústria não investe em um ramo tão promissor e potencialmente lucrativo como a dos medicamentos homeopáticos e fitoterápicos que já conta com centenas de milhões de consumidores?

\footnotetext{
${ }^{3}$ A Escola de Saúde Pública de Harvard e o Hospital Beth Israel, afiliado à Faculdade de Medicina de Harvard, publicaram, recentemente, os resultados de um estudo conduzido por Michelle Dossett, MD, PhD, e colaboradores, incluindo o expert em placebo Ted Kaptchuk, $\mathrm{OMD}$, no qual concluem que os estudos conduzidos usando a homeopatia "sugerem potencial benefício para a saúde publica como redução de uso desnecessário de antibioticoterapia, redução de custos para tratar de algumas doenças do trato respiratório, melhora nas depressões relacionadas ao período do pós- menopausa, melhora os resultados na saúde de indivíduos com moléstias crônicas e controle de doenças epidêmicas como, por exemplo, a epidemia de leptospirose em Cuba.
} 


\section{Arquivo Maaravi}

Um dos problemas para os interesses mercantis na produção de medicamentos está no fato de que, por exemplo, as substâncias medicinais homeopáticas não têm patente, isso é, constituem um bem público. Trata-se, portanto, de um conjunto de medicamentos que foram incorporados ao patrimônio da humanidade, já que nenhuma indústria ou indivíduo detém os direitos de propriedade dessas substâncias. Isso significa que sobre esses fármacos não incidem royalties. Exatamente isso que você acaba de ler: nenhuma substância usada nos fármacos empregados na homeopatia possui domínio de patente. Isso explica seu relativo baixo custo. Isso também explica a quantidade desproporcional de ataques dirigidos contra ela e sua relativa incapacidade de responder a eles com pesquisas subsidiadas.

Evidentemente, existem outras dificuldades: a natureza sectária de parte do establishment das medicinas integrativas. Numa compreensível atitude defensiva que emergiu contra as décadas de acusações de ineficácia das doses ultradiluídas, existe nesse meio, relutância em fazer a autocrítica necessária para se antecipar e apontar suas próprias deficiências, lacunas e limites de atuação.

Existem praticantes que insistem numa lógica autossuficiente que clama para a medicina integrativa uma emancipação total das demais racionalidades. E existem aqueles que aceitam abrir mão da teoria que organiza e confere alguma consistência teórica para o método. Porém, para qualquer medicina de inspiração vitalista não se pode resumir os benefícios apenas ao "resultado clínico pontual", mas ao conjunto de potenciais benefícios para a totalidade da pessoa enferma.

O dilema é compreensível: se por um lado, ela se apresenta como uma outra lógica médica, por outro, ela precisa, em parte, assimilar-se à cultura científica corrente se quiser ser levada a sério. Isso significa que a medicina integrativa acaba falhando em se estabelecer, tanto na prática privada quanto no setor publico, pois não consegue nem evidenciar claramente sua performance clínica, nem se fazer entender pela linguagem contemporânea. Um impasse, que no caso específico da homeopatia, dura quase dois séculos.

O erro fundamental está numa certa recusa inconsciente dessas correntes em aceitar que de uma forma ou de outra a única saída para que uma tese seja aceita nas sociedades contemporâneas é sua penetração na cultura por intermédio das pesquisas acadêmicas e da discussão com a sociedade. Somente esse pertencimento à cultura garantiria a permanência de uma formulação sofisticada como é a proposta de uma terapêutica pautada no uso dos semelhantes.

Sofisticada, porque pretende, inclusive, retomar um assunto dos mais importantes, e, ao mesmo tempo uma das questões científicas mais negligenciadas da medicina: ainda são raras e escassas pesquisas sobre o como as pessoas se curam.

Notem que, na atualidade, já existem núcleos de pesquisa médica que discutem criticamente a validade dos protocolos padrões. O cálculo de risco para alguns 
procedimentos terapêuticos tem sofrido questionamentos. E uma boa parcela dos pesquisadores já leva cada vez mais a sério o fenômeno chamado superdiagnóstico. ${ }^{4}$

As medicinas integrativas devem ser apresentadas não só como alternativas - com todas as suas conotações contraculturais -, mas como um processo que dialoga ao mesmo tempo com a ciências naturais como com as várias áreas das humanidades como a antropologia, filosofia e psicologia. Simultaneamente, precisa ser mais enfática em sua proposta: estabelecer bases teóricas próprias para uma medicina do sujeito emancipada, por exemplo, das teorias psicanalíticas e das mistificações. Portanto, ela deveria ocupar o centro da discussão das ciências humanas com as ciências biológicas. Temos tempo. Sejamos todos pacientes, a discussão está apenas começando.

Recebido em: 10/07/2020.

Aprovado em: 17/07/2020.

${ }^{4}$ Overdiagnosed - cuja tradução poderia se aproximar de "superdiagnosticado". Caracteriza-se em valorizar excessivamente os exames subsidiários e atribuir importância exagerada aos distúrbios clínicos que talvez não merecessem tratamento, pois seriam patologias inofensivas ou "amigáveis". O custo orgânico e psíquico de determinados procedimentos terapêuticos é simplesmente elevado demais para os pacientes. 